\title{
Leptin and zeranol up-regulate cyclin D1 expression in primary cultured normal human breast pre-adipocytes
}

\author{
PINGPING XU ${ }^{1 *}$, WEIPING YE ${ }^{1 *}$, SAIYI ZHONG ${ }^{1,4}$, HONG LI $^{1,2}$, ERIC FENG $^{1}$, \\ SHU-HONG LIN ${ }^{1}$, CHIEH-TI KUO ${ }^{1}$, JIE-YU LIU ${ }^{1}$ and YOUNG C. LIN ${ }^{1,3}$ \\ ${ }^{1}$ Laboratory of Reproductive and Molecular Endocrinology, College of Veterinary Medicine; \\ ${ }^{2}$ Division of Pharmaceutical Science, College of Pharmacy, The Ohio State University; ${ }^{3}$ The Ohio State University \\ Comprehensive Cancer Center, Columbus, OH 43210, USA; ${ }^{4}$ College of Food Science and \\ Nutritional Engineering, China Agricultural University, Beijing 100083, P.R. China
}

Received May 28, 2010; Accepted August 17, 2010

DOI: $10.3892 / \mathrm{mmr} .2010 .370$

\begin{abstract}
Adipocytes account for more than $90 \%$ of human breast volume and secrete adipocytokines, which play a role in breast cancer development. Among the adipocytokines is leptin, which is secreted mainly by adipocytes and plays a key role in breast cancer development. Leptin expression is up-regulated in both obese and breast cancer patients, and promotes breast cancer cell growth. Exposure to environmental estrogens has also been found to be directly related to the development of breast cancer. Zeranol $(\mathrm{Z})$ is a non-steroidal anabolic growth promoter with estrogenic activity that is widely used in the US beef industry due to its commercial benefits. Gossypol is a natural compound extracted from cottonseed that inhibits breast cancer growth, and is potentially a chemopreventive food component. This study focused on $\mathrm{Z}$ and bio-active Z-containing sera (ZS) collected from $Z$-implanted beef, and evaluated their adverse health risk to humans. We hypothesized that $\mathrm{Z}$ increases the risk of breast cancer in obese women. A cell proliferation assay, ELISA analysis, RT-PCR and Western blotting were performed to investigate the interaction of leptin, $\mathrm{Z}$ and (-)-gossypol in primary cultured normal human breast preadipocytes. The results indicated that $\mathrm{Z}$ and ZS stimulated the growth of pre-adipocytes isolated from normal human breast tissues by up-regulating cyclin D1 expression, while (-)-gossypol reversed this effect.
\end{abstract}

Correspondence to: Dr Young C. Lin, Laboratory of Reproductive and Molecular Endocrinology, College of Veterinary Medicine, The Ohio State University, Columbus, OH 43210, USA

E-mail: lin.15@osu.edu

${ }^{*}$ Contributed equally

Key words: zeranol, leptin, (-)-gossypol, breast cancer, primary cultured human normal breast pre-adipocytes

\section{Introduction}

Breast cancer is the most frequently occurring cancer in women in the US. According to clinical cancer statistics, it is estimated that 192,370 new cases arose and 40,170 individuals succumbed to breast cancer in 2009 (1). Epidemiological studies suggest that there are many risk factors associated with the occurrence of breast cancer, including dietary fat and environmental estrogenic endocrine disruptors. Exposure to environmental estrogens has been found to be directly related to the increase in breast cancer incidence. Estrogen has been regarded as a positive regulator of leptin (2), which is mainly secreted by adipocytes and plays a key role in breast cancer development. Zeranol $(Z)$ is a non-steroidal anabolic growth promoter with estrogenic activity, widely used in the US beef industry for improving weight gain, feed efficiency and marbling. It has been reported that $\mathrm{Z}$ stimulates the proliferation of primary cultured normal human breast cells and MCF-7 cells (3). We also found that $2.5 \%$ of Z-containing sera (ZS) harvested from 60-day post $72 \mathrm{mg} \mathrm{Z}$ pellets implanted beef cattle are capable of transforming the normal human breast epithelial cell line MCF-10A to neoplastic breast cancer cells in a 21-day culture (unpublished data).

Another known risk factor for breast cancer is obesity, which has become a major public health concern in the US. The incidence of breast cancer is increased by $30-50 \%$ in obese cancer patients as compared to cancer patients with average weight. Morbidity is also increased in obese cancer patients as compared to cancer patients with average or low weight (4). The molecular links between breast cancer and obesity have been studied for many years (5). The condition of obesity is characterized by an increase in fat cell number, fat cell size, or a combination of the two (6). It is assumed that a gradual accumulation of body fat after birth is mainly due to increasing fat cell size, not number. Total fat cell number also increases, but only in severe obesity (6).

Adipocytes are known to be extremely stable, with food restriction alone leading to a decrease in adipocyte size, but not number (7). Leptin, mainly secreted by adipocytes, is a product of the obese (ob) gene and plays a key role during 
pregnancy and fetal development (6). One of the major functions of leptin is to regulate energy balance and appetite regulation (food intake) (6). It targets the brain to increase loss of adipose tissue by increasing adipocyte apoptosis.

In human breast tissue, adipocytes account for approximately $90 \%$ of the bulk, while epithelial cells make up only $10 \%$ (4). Fat tissue contains small and large adipocytes, as well as stromal and endothelial cells (6). Various hormones, such as insulin and sex steroids, have been associated with dynamic changes in adipose tissue and are believed to contribute to the signals that cause adipocyte differentiation (6). An increase in breast cancer risk is associated with higher body mass index levels, and is restricted to women with estrogen receptor (ER)-positive tumors (8). Obesity is not associated with a leptin deficiency, but rather with resistance to leptin (9). Leptin was found to increase the estradiolinduced activation of $E R \alpha$, suggesting that leptin and estrogen may cooperate in the growth of estrogen-dependent breast cancer cells (9). Chen et al also found that leptin increases ZR-75-1 breast cell growth by up-regulating cyclin D1 and down-regulating P53 (10). As leptin stimulates estrogen biosynthesis through the induction of aromatase activity and modulation of ER $\alpha$ activity, it has been characterized as a growth factor for breast cancer $(11,12)$. High levels of leptin in obese breast cancer patients may play a crucial role in breast cancer cell proliferation, invasion and metastasis (8). Leptin has a direct mitogenic effect on human breast cancer cells (13); therefore, the inhibition of leptin may contribute to the prevention and treatment of breast cancer (14). In addition to its mitogenic effects, leptin promotes the proliferation of the T47-D cell line (15), and may contribute to the development of a more aggressive malignant phenotype (16). ICI 182,780 is a pure estrogen antagonist approved for the treatment of breast cancer patients who fail to respond to tamoxifen therapy. Leptin may be involved in the resistance of breast cancer cells to anti-estrogen therapies (17).

In general, adipose tissue mass is determined by a balance of lipolysis, lipogenesis and adipocyte proliferation. Adipogenesis is a complex process of pre-adipocyte differentiation, whose mechanism is still not fully understood. Researchers have found that leptin does not act directly to induce adipocyte apoptosis, but rather acts centrally to initiate a signal to the adipose tissue, causing apoptosis (18). Leptin had no effects on the apoptosis of either pre-adipocytes or mature adipocytes within a 24- or 48-h incubation in 3T3-L1 adipocytes, but acted directly to inhibit the maturation of preadipocytes and suppressed lipid accumulation during 3T3-L1 differentiation (18).

Gossypol is a natural polyphenolic compound extracted from cottonseed that is used as an anticancer chemopreventive agent due to its inhibition of the growth of various types of cancer, including colon (19), prostate (20) and breast cancer $(21,22)$. It has been suggested that gossypol is a potential chemopreventive food component. Our laboratory also demonstrated that gossypol exhibits anticancer activity against multidrug-resistant human breast cancer cells (22), with (-)-gossypol having the strongest effect among the three isoforms (data not shown). We also found that (-)-gossypol counteracts leptin- and Z-induced human breast cancer epithelial cells by down-regulating cyclin D1 expression (3).
This study focused on $\mathrm{Z}$ and bio-active ZS collected from Z-implanted beef and, evaluated their adverse health risk to human beings. The intervention of leptin, Z, ZS and (-)-gossypol in the growth of primary cultured normal human breast pre-adipocytes (HNBPADs) was also investigated. We hypothesized that $\mathrm{Z}$ increases the growth of HNBPADs and has adverse health effects, particularly in obese women.

\section{Materials and methods}

Animals and blood sampling. Ralgro Magnum ${ }^{\circledR}$ (RM; commercial Z pallet) was purchased from Schering-Plough Corp. (Kenilworth, NJ, USA) in the form of cartridges, each containing $72 \mathrm{mg}$ of Z. Twenty cross-bred Angus beef heifers $(\sim 1$ year old) purchased from the Department of Animal Science were randomly divided into two groups according to their initial body weight. Animals were treated according to our previously described protocol (23). Sera dropped from the Z-implanted beef at day 0 (ZS-D0, before Z implantation) and 30 days post $Z$ implantation (ZS-D30) were sterilized using a $50 \mathrm{ml}$ conical filter tube and stored at $-20^{\circ} \mathrm{C}$.

Reagents. Recombinant human leptin was ordered from R\&D Systems (Minneapolis, MN, USA) and was prepared as a $1 \mathrm{mg} /$ $\mathrm{ml}$ stock solution in $20 \mathrm{mM}$ sterile Tris/ $\mathrm{HCl}, \mathrm{pH} 8.0$, at $-20^{\circ} \mathrm{C}$. (-)-gossypol was provided by the USDA Southern Regional Research Center (New Orleans, LA, USA) and was prepared as a $50 \%$ stock solution in dimethyl sulfoxide (DMSO). Z was purchased from Sigma Chemical Co. (St. Louis, MO, USA).

Normal human breast tissues. Normal human breast tissues were obtained through the Tissue Procurement Program of the Ohio State University Comprehensive Cancer Center Hospital (Columbus, OH, USA). At the time of procurement, the tissue samples were placed in Dulbecco's modified Eagle's medium and Ham's F12 medium (1:1) (DMEM/F12) without phenol red (Sigma Chemical Co.) and stored at $4^{\circ} \mathrm{C}$ before being transferred to the laboratory.

Tissue culture and primary cultured normal human breast pre-adipocyte isolation. Normal human breast tissues were sterilized in $70 \%$ ethanol for $30 \mathrm{sec}$ and then washed three times with fresh DMEM/F12. Subsequently, the normal human breast tissues were treated with leptin at $0,1.5$, 3.0 and $6.0 \mathrm{nM}$ in DMEM/F12 medium supplemented with $10 \%$ dextran-coated charcoal (DCC) stripped fetal bovine serum (FBS) and cultured in a $10-\mathrm{cm}^{2}$ cell culture plate in a humidified incubator $\left(5 \% \mathrm{CO}_{2}, 95 \%\right.$ air, $\left.37^{\circ} \mathrm{C}\right)$ for 96 h. The medium was changed every $48 \mathrm{~h}$. Following a $96-\mathrm{h}$ culture, the normal human breast tissues were minced, then the primary cultured normal human breast epithelial cells (HBNECs) and HNBPADs were isolated using a previously described method (23).

Cell culture. The isolated primary cultured HNBPADs were allowed to attach and were then cultured in a $75-\mathrm{cm}^{2}$ culture flask in a humidified incubator $\left(5 \% \mathrm{CO}_{2}, 95 \%\right.$ air, $\left.37^{\circ} \mathrm{C}\right)$ with $10 \mathrm{ml}$ of the DMEM/F12 mixture (Atlanta Biologicals, Norcross, GA, USA) supplemented with 10\% FBS (Invitrogen, Carlsbad, CA USA). The DMEM/F12 medium was changed 
every 2 days. When the cells achieved 85-90\% confluence, they were washed with $10 \mathrm{ml}$ of calcium- and magnesium-free phosphate buffered saline (PBS; pH 7.3) and then trypsinized with $3 \mathrm{ml}$ of $0.25 \%$ trypsin and $5.3 \mathrm{mM}$ EDTA (Invitrogen) for $10 \mathrm{~min}$ at $37^{\circ} \mathrm{C}$. The trypsinization was stopped by the addition of $10 \mathrm{ml}$ of DMEM/F12 medium with $10 \%$ FBS. Following centrifugation, the dissociated cells were re-suspended in high-calcium DMEM/F12 medium with $10 \%$ FBS and sub-cultured into $75-\mathrm{cm}^{2}$ culture flasks at a ratio of 1:5. The experiments were conducted on primary cultured HNBPADs not generated beyond the fourth passage.

Cell proliferation (MTT) assay. Four thousand HNBPADs isolated from non-leptin, 1.5- and 6-nM leptin cultured tissues were seeded in each well of a 96-well plate in DMEM/F12 medium at a total volume of $100 \mu \mathrm{l}$ and incubated at $37^{\circ} \mathrm{C}$ for $24 \mathrm{~h}$. The following day, the medium was replaced with $100 \mu \mathrm{l}$ DMEM/F12 supplemented with $0.2 \%$ BSA followed by incubation at $37^{\circ} \mathrm{C}$ for another $24 \mathrm{~h}$. HNBPADs were treated with $0.4,0.8$ and $1.6 \mathrm{nM}$ leptin and 0, 2.5, 5, 10 and $20 \mathrm{nM}$ $\mathrm{Z}, \mathrm{ZS}-\mathrm{D} 0$ or ZS-D30 at $0.2,1$ and $5 \%$ in culture medium for $24 \mathrm{~h}$. Control cells were cultured in $0.1 \%$ DMSO. The proliferation of HNBPADs was measured by adding $20 \mu \mathrm{l}$ of a fresh mixture of 3-(4,5-dimethylthiazol-2-yl)-5-(3carboxymethoxy-phenyl)-2-(4-sulfophenyl)-2H-tetrazolium (MTS) and phenazine methosulfate solution (20:1) (Promega, Madison, WI, USA) to each well. Following incubation at $37^{\circ} \mathrm{C}$ for $1-3 \mathrm{~h}$, the OD values were measured using a kinetic microplate reader (Molecular Devices Cooperation, Menio Park, CA, USA) at a wavelength of $490 \mathrm{~nm}$, and cell growth was compared. The sensitivity dose of HNBPADs to leptin for each patient was calculated, then the average sensitivity dose for the patients was determined.

Primary cultured HBNECs were also tested using the method described above, but with a low-calcium $(0.04 \mathrm{mM}$ $\mathrm{CaCl}_{2}$ ) DMEM/F12 mixture (Atlanta Biologicals) supplemented with 10\% Chelex-100 (Bio-Rad Laboratories, Richmond, CA, USA) treated FBS (Invitrogen) instead of the DMEM/F12 mixture supplemented with 10\% FBS. HBNECs was treated with $0.75,1.5,3$ and $6 \mathrm{nM}$ leptin for $24 \mathrm{~h}$. Control cells were instead cultured in $0.1 \%$ DMSO. After $24 \mathrm{~h}$, the cell proliferation assay was performed as described above. HNBPADs isolated from two patients and HBNECs from seven patients were tested, and the average sensitivity dose of the HNBPADs and HBNECs to leptin was calculated and compared.

Cell treatment. Viable HNBPADs (1x105/well) isolated from non-leptin cultured tissues were seeded in 6-well plates in $5 \mathrm{ml}$ DMEM/F12 supplemented with 10\% FBS medium. After $24 \mathrm{~h}$, the medium was replaced with DMEM/F12 supplemented with $10 \%$ DCC stripped FBS. The cells were cultured for a further $24 \mathrm{~h}$, then treated with serum harvested from heifers. The control serum was harvested from heifers with ZS-D0, and the experimental serum was harvested from the same heifers with ZS-D30 at day 30. The concentrations of ZS-D0 and ZS-D30 was 0.2, 1.0 and 5.0\% in the culture medium. The 24-h treatment was $0.5,1$ and $2 \mathrm{nM}$ leptin alone, and 2.5, 5 and $10 \mathrm{nM} \mathrm{Z}$ alone for HNBPADs isolated from non-leptin cultured tissue. The cells were also treated with $1.5 \mathrm{nM}$ leptin, $3 \mathrm{nM} \mathrm{Z}$ and $3 \mu \mathrm{M}$ (-)-gossypol, alone or combination for $24 \mathrm{~h}$, and cyclin D1 expression was measured. Control cells were cultured in $0.1 \%$ DMSO.

Pre-adipocyte mRNA isolation and cDNA synthesis. After HNBPADs had been treated for $24 \mathrm{~h}$, the total RNA was isolated in $1 \mathrm{ml}$ TRIzol Reagent (Invitrogen) according to the manufacturer's instructions. RNA concentration was measured using a DU-70 spectrophotometer (Beckman Instruments Inc., Fullerton, CA, USA). RNA ( $1 \mu \mathrm{g})$ from cultured cells was reverse transcribed with 200 units of M-MLV Reverse Transcriptase (Invitrogen) at $37^{\circ} \mathrm{C}$ for $50 \mathrm{~min}$, then at $70^{\circ} \mathrm{C}$ for $15 \mathrm{~min}$ in the presence of $1 \mu 110 \mathrm{mM}$ dNTP $(10 \mathrm{mM}$ each dATP, dGTP, dCTP and dTTP at a neutral pH) (Invitrogen), $1 \mu \mathrm{l} 50 \mu \mathrm{M}$ random hexamer (Amersham Pharmacia Biotech, Piscataway, NJ, USA), RNase Inhibitor (Invitrogen), $10 \mu 15 \mathrm{X}$ First Strand buffer, $5 \mu \mathrm{l} 0.1 \mathrm{M}$ DTT and $1 \mu \mathrm{l}$ RNase Inhibitor (Invitrogen) in a total volume of $50 \mu \mathrm{l}$ in a gradient mastercycler (Eppendorf ${ }^{\circledR}$, Westbury, NY, USA).

Reverse transcription-polymerase chain reaction. RT-PCR conditions were optimized for every primer pair and performed with a thermocycler Gene Amp PCR (Eppendorf ${ }^{\circledR}$ ). The newlysynthesized cDNA $(2 \mu \mathrm{l})$ was used as a template for RT-PCR with the addition of 1 unit platinum Taq DNA polymerase (Invitrogen) for a total volume of $25 \mu \mathrm{l}$. $\mathrm{MgCl}_{2}$ concentration, annealing temperature and cycle number for the amplification of the PCR product, cyclin D1 and 36 B4, were optimized. The primer sequences for cyclin D1 were 5'-GCT CCT GTG CTG CGA AGT GG-3' (sense) and 5'-TGG AGG CGT CGG TGT AGA TG-3' (antisense) (product size 372 bp). PCR conditions were denaturing at $95^{\circ} \mathrm{C}$ for $5 \mathrm{~min}, 27$ cycles of $94^{\circ} \mathrm{C}$ for $45 \mathrm{sec}, 54^{\circ} \mathrm{C}$ for $45 \mathrm{sec}, 72^{\circ} \mathrm{C}$ for $60 \mathrm{sec}$, then extension at $72^{\circ} \mathrm{C}$ for $10 \mathrm{~min}$. The primer sequences for $36 \mathrm{~B} 4$ were 5'- AAA CTG CTG CCT CAT ATC CG-3' (sense) and 5'- TTT CAG CAA GTG GGA AGG TG-3' (antisense) (product size 563 bp). PCR conditions were denaturing at $95^{\circ} \mathrm{C}$ for $5 \mathrm{~min}, 24$ cycles of $95^{\circ} \mathrm{C}$ for $60 \mathrm{sec}, 63^{\circ} \mathrm{C}$ for $60 \mathrm{sec}, 72^{\circ} \mathrm{C}$ for $60 \mathrm{sec}$, then extension at $72^{\circ} \mathrm{C}$ for $10 \mathrm{~min} .36 \mathrm{~B} 4$ was used as an internal control whose RNA was unmodified by the treatment.

The final RT-PCR products $(10 \mu \mathrm{l})$ mixed with $1 \mu \mathrm{l} 10 \mathrm{X}$ loading buffer were separated on $1.5 \%$ agarose gel and visualized by staining with ethidium bromide. Electronic images were captured using a FUJIFILM LAS-3000 image system (Fujifilm Medical Systems USA, Inc., Stanford, CT, USA). The densities of specific bands were quantified using ImageQuant software (Molecular Dynamics, Sunnyvale, CA, USA). The results were presented as the ratio of cyclin D1 to $36 \mathrm{~B} 4$.

Western blotting. Primary cultured HNBPADs were separately seeded in a 100-mm dish $\left(1 \times 10^{6}\right.$ cells/dish) in DMEM/F12 medium supplemented with $10 \%$ FBS and cultured overnight. The medium was then replaced with DMEM/F12 supplemented with DCC-stripped 10\% FBS. After being cultured for $24 \mathrm{~h}$, the cells were treated with $0.1 \%$ DMSO as a vehicle control, 0.5 and $1 \mathrm{nM}$ leptin and 2.5, 5 and $10 \mathrm{nM} \mathrm{Z}$ in DMEM/ F12 supplemented with $10 \%$ FBS medium for $24 \mathrm{~h}$. Cells in each dish were lysed by the addition of $0.5 \mathrm{ml}$ of M-PERTM Mammalian Protein Extraction Reagent (Thermo Fisher Scientific Inc., Rockford, IL, USA) and $5 \mu 1$ 100X protease 
inhibitor (Thermo Fisher Scientific Inc.). The dishes were gently agitated on an orbital shaker at $4^{\circ} \mathrm{C}$ for $15 \mathrm{~min}$. Then, the cell lysate was collected into a microcentrifuge tube and the samples were centrifuged at $27,000 \times \mathrm{g}\left(4^{\circ} \mathrm{C}\right.$ for $\left.10 \mathrm{~min}\right)$ to pellet the cell debris. Finally, the supernatant layer containing the proteins was transferred to a clean tube for analysis. The concentration of total protein was determined using the Micro BCATM Protein assay (Pierce, Rockford, IL, USA) according to the manufacturer's instructions. Protein $(50 \mu \mathrm{g})$ from each sample was mixed with an appropriate volume of $3 \mathrm{X}$ Laemmli sample buffer $(62.5 \mathrm{mM}$ Tris- $\mathrm{HCl}, \mathrm{pH} 6.8,2 \%$ SDS, $25 \%$ glycerol, $0.01 \%$ Bromophenol blue) (Bio-Rad Laboratories) and was then denatured at $100^{\circ} \mathrm{C}$ for $5 \mathrm{~min}$. The mixtures were loaded onto ready gel $10 \%$ Tris- $\mathrm{HCl}$ Gel for SDS-PAGE (Bio-Rad Laboratories) and electrophorsed at 100 volts for $\sim 1 \mathrm{~h}$ in $1 \mathrm{X}$ Tris/Glycine/SDS buffer $(25 \mathrm{mM}$ Tris- $\mathrm{HCl}, 250 \mathrm{mM}$ glycine, $0.1 \%$ SDS, $\mathrm{pH}$ 8.3). The separated proteins were than transferred to a piece of polyvinylidene fluoride (PVDF) membrane in a Semi-Dry Blotting Unit (Bio-Rad Laboratories) under a current density of $0.8 \mathrm{~mA} / \mathrm{cm}^{2}$ for an approximate time according to the manufacturer's instructions. After the protein was transferred, the membrane was immediately soaked in $100 \%$ methanol for $10 \mathrm{sec}$ and then placed on a piece of filter paper until dry. Subsequently, the membrane was blocked in PBST (PBS + 0.1\% Tween-20) solution containing 10\% non-fat milk and incubated at $4^{\circ} \mathrm{C}$ overnight, then rinsed with PBST and blotted with primary antibody as follows: cyclin D1 antibody (1:500 dilution, sc-246, mouse monoclonal antibody) or $\beta$-actin antibody (1:1,000 dilution, sc-1615, affinity-purified goat polyclonal antibody; Santa Cruz Biotechnology, Inc.), followed by incubation at room temperature for $1 \mathrm{~h}$. The membrane was then rinsed with PBST and incubated with secondary antibody as follows: ECL anti-mouse IgG linked to horseradish peroxidase (HRP) (1:1,000 dilution, sc2020; Santa Cruz Biotechnology, Inc.) or a donkey anti-goat IgG HRP (1:1,000 dilution, NA931V; Amersham Biosciences) for $1 \mathrm{~h}$. The membrane was rinsed again with PBST and incubated for 5 min with $1 \mathrm{ml}$ ECL-Plus Western blotting detection reagents (Amersham Pharmacia Biotech). Images were captured using the FUJIFILM LAS-3000 image system (Fujifilm Medical Systems USA, Inc.). The densities of specific bands were quantified using ImageQuant software (Molecular Dynamics).

Leptin measurement. Viable HNBPADs (3x105/well) isolated from non-leptin cultured tissues were seeded in $100-\mathrm{mm}$ plates in $10 \mathrm{ml}$ DMEM/F12 supplemented with 10\% FBS medium. After $24 \mathrm{~h}$, the medium was replaced with DMEM/F12 supplemented with $10 \%$ DCC stripped FBS, and cells were cultured for a further $24 \mathrm{~h}$. Subsequently, the primary culture HNBPADs were treated with $2.5 \mathrm{nM} \mathrm{Z}$ for $24 \mathrm{~h}$, culture media were collected and leptin measurement was conducted using human leptin immunoassay kits (R\&D Systems). The particulates in the cell culture supernates were removed by centrifugation at 1,200 rpm for $5 \mathrm{~min}$ followed immediately by assay according to the manufacturer's instructions. The assay was stopped by the addition of $50 \mu \mathrm{l}$ stop solution to each well, OD values were measured within 30 min using a kinetic microplate reader (Molecular Devices Cooperation) at a wavelength of $450 \mathrm{~nm}$, and the leptin concentration in the culture medium was calculated.

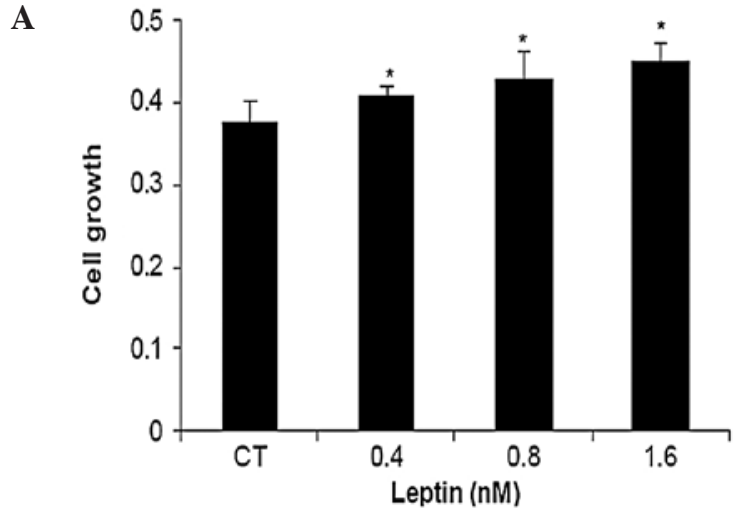

B

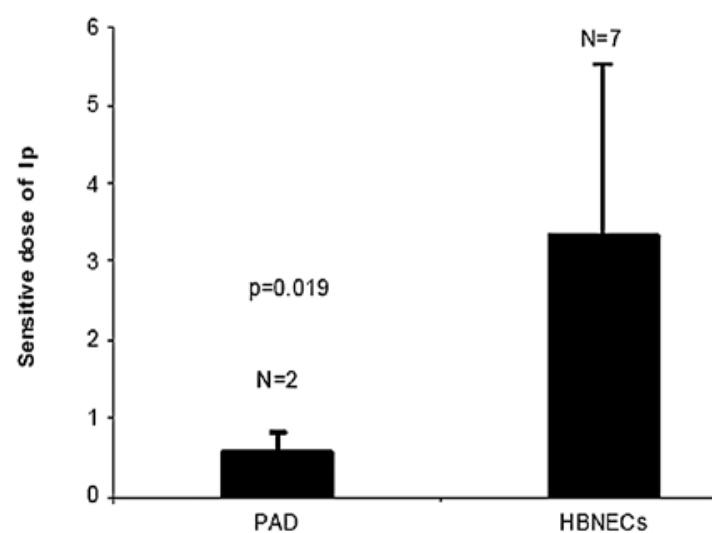

Figure 1. (A) Effect of leptin on pre-adipocyte growth. Primary cultured normal human breast pre-adipocytes were isolated from non-leptin cultured tissues and treated with $0.4,0.8$ and $1.6 \mathrm{nM}$ leptin for $24 \mathrm{~h}$, then cell growth was measured. *Significant differences in HNBPADs growth compared to the control group $(\mathrm{p}<0.05)$. (B) Comparison of the average effective dose of leptin in the HNBPADs and HBNECs. Primary cultured HNBPADs isolated from two patients and HBNECs from seven patients were tested for their minimum sensitive dose to leptin, then the average sensitive dose to leptin was calculated and compared. The HNBPADs were more sensitive to leptin than the HBNECs at the level of $\mathrm{p}<0.05(\mathrm{p}=0.019)$.

Statistical analysis. The results of the cell proliferation assay are presented as the relative cell growth compared to the control group \pm standard deviation (SD) for four replicate culture wells. The results of mRNA expression are presented as the ratio of cyclin D1 to $36 \mathrm{~B} 4$ compared to the control group \pm SD for three replicate culture wells. Analysis was performed using Minitab 15 software (Minitab Inc., PA, USA). Statistical differences were determined using two sample t-test analyses for cell proliferation and a one-way ANOVA analysis for mRNA expression. A p-value of $<0.05$ was considered statistically significant.

\section{Results}

Leptin stimulates primary cultured HNBPAD growth in a dose-dependent manner. As shown in Fig. 1A, primary cultured HNBPADs are sensitive to $0.4 \mathrm{nM}$ of leptin in a dose-dependent manner. Compared to HBNECs, the average effective dose of leptin in was significantly lower HNBPADs than in HBNECs (Fig. 1B).

$Z$ stimulates primary cultured HNBPAD growth. As shown in Fig. 2A, Z stimulated the proliferation of primary cultured 
A

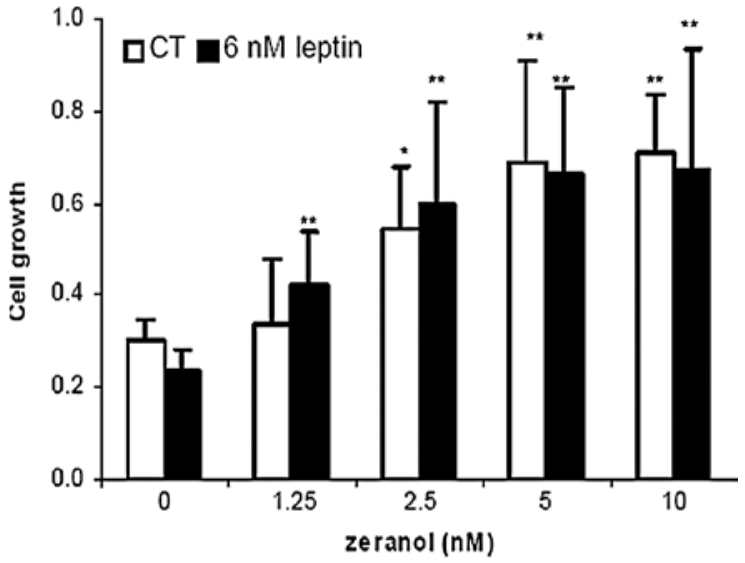

B
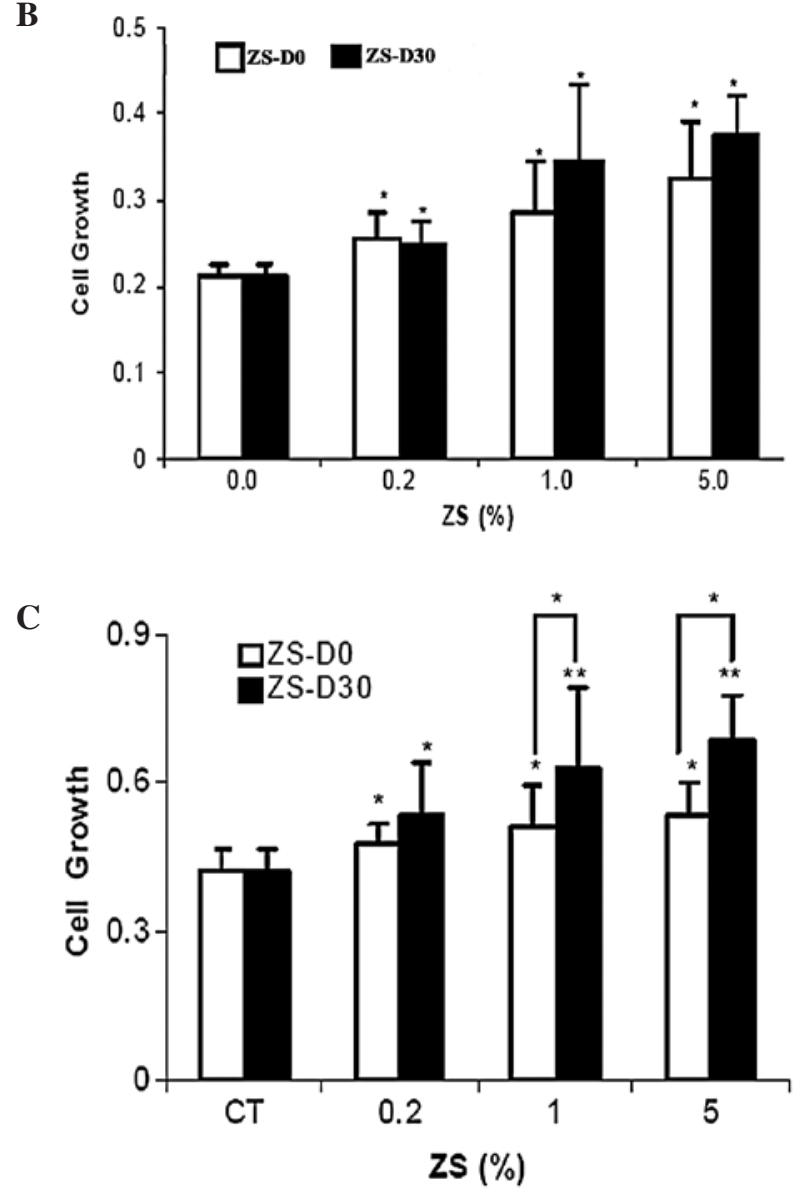

Figure 2. (A) Changes in HNBPAD sensitivity to $\mathrm{Z}$ with leptin exposure. Primary cultured normal human breast pre-adipocytes were isolated from non-leptin and 6-nM leptin cultured tissues and treated with 1.25, 2.5, 5 and $10 \mathrm{nM} \mathrm{Z}$ for $24 \mathrm{~h}$, then cell growth was measured. Z (1.25 nM) significantly increased the proliferation of HNBPADs exposed to $6 \mathrm{nM}$ leptin, and $2.5 \mathrm{nM}$ $\mathrm{Z}$ began to significantly increase the proliferation of HNBPAD isolated from non-leptin cultured tissues. (B) The effect of ZS-D0 and ZS-D30 on the proliferation of pre-adipocytes isolated from non-leptin cultured tissues. Primary cultured HNBPADs isolated from non-leptin cultured tissues were treated with ZS-D0 and ZS-D30 at $0.2,1$ and 5\% in culture medium for $24 \mathrm{~h}$, and cell growth was measured. All treatments significantly increased cell growth. However, there was no significant difference between groups treated with ZS-D0 and ZS-D30 at all doses. (C) Comparison of the effect of ZS-D0 and ZS-D30 on the proliferation of pre-adipocytes isolated from 6-nM leptin cultured tissues. Primary cultured HNBPADs isolated from 6-nM leptin cultured tissues were treated with ZS-D0 and ZS-D30 at 0.2, 1 and $5 \%$ in culture medium for $24 \mathrm{~h}$, and cell growth was measured. *Significant differences in HNBPAD growth compared to the control group $(\mathrm{p}<0.05)$. ${ }^{* *}$ Significant difference between cells treated with ZS-D0 and ZS-D30 in the 1 and $5 \%$ groups $(\mathrm{p}<0.05)$.
HNBPADs isolated from both non-leptin and 6-nM leptin cultured tissues as compared to their respective control groups. Compared to the control group, $\mathrm{Z}$ at $\geq 2.5 \mathrm{nM}$ significantly increased the proliferation of HNBPADs isolated from non-leptin cultured tissue, and HNBPADs isolated from 6-nM leptin cultured tissue were responsive to a $\geq 1.25 \mathrm{nM}$ concentration of $\mathrm{Z}$.

ZS stimulates primary cultured HNBPAD growth. Compared to the control group, all treatments increased HNBPAD growth, but there was no significant difference between groups treated with ZS-D0 and ZS-D30 at all doses in the proliferation of HNBPADs isolated from non-leptin cultured tissue (Fig. 2B). Compared to the control group, treatment with all doses of ZS-D0 and ZS-D30 significantly increased the proliferation of pre-adipocytes isolated from 6-nM leptin cultured tissue (Fig. 2C). There was a significant difference in cell growth between groups treated with ZS-D0 and ZS-D30 at a concentration of 1 and $5 \%$ in cultured medium in the preadipocytes isolated from the 6-nM leptin cultured tissue.

$Z$ and leptin increase cyclin Dl expression. As shown in Fig. 3A, cyclin D1 expression was up-regulated by leptin treatment in HNBPADs. Leptin at 1 and $2 \mathrm{nM}$ significantly increased cyclin D1 mRNA expression in the HNBPADs. Moreover, $3 \mathrm{nM} \mathrm{Z}$ and the combination of $3 \mathrm{nM} \mathrm{Z}$ with $1.5 \mathrm{nM}$ leptin up-regulated cyclin D1 expression in the HNBPADs, but (-)-gossypol counteracted this effect. A significant difference was found between the combination groups treated with and without $3 \mu \mathrm{M}$ (-)-gossypol (Fig. 3B). Z at 2.5,5 and $10 \mathrm{nM}$ and leptin at 0.5 and $1 \mathrm{nM}$ up-regulated cyclin D1 protein expression (Fig. 3C and D).

$Z$ increased leptin secretion of HBNECs. As shown in Fig. 4, $2.5 \mathrm{nM} \mathrm{Z}$ significantly increased the leptin secretion of HNBECs as compared to the control group $(\mathrm{p}<0.05)$.

\section{Discussion}

Cyclin D1 is a cell cycle regulator that plays a key role in cell growth. The cyclin-dependent kinases (CDKs) cannot regulate cell growth without the cyclin subunit. By binding to cyclin D, cyclin D-CDK 4/6 constitutes the engine of the cell cycle machinery and affects the G1 phase of cell growth. Among several cyclins, cyclin D1 protein plays a key role in regulating the progress of the cell during the G1 phase of the cell cycle (24). Cyclin D1-CDK4 complexes are known to phosphorylate $\mathrm{Rb}$ and $\mathrm{Rb}$-like proteins, which release a transcription factor $(\mathrm{E} 2 \mathrm{~F})$ that has resultant effects on gene transcription. Researchers have found that cyclin D1 expression is strongly associated with ER positivity. Cyclin D1 was found to be overexpressed in up to $50 \%$ of human breast cancer cases (24). The overexpression of cyclin D1 was found to be statistically correlated with ER positivity and well-differentiated tumors, and was observed in $79 \%$ of ER-positive tumors and $45 \%$ of ER-negative tumors (24). In the earliest proliferative epithelial lesions of the breast, cyclin D1 expression was detected at levels significantly higher than those in normal breast epithelium, with a further significant increase accompanying the progression to any form of cancer $(25,26)$. Cyclin D1 protein 

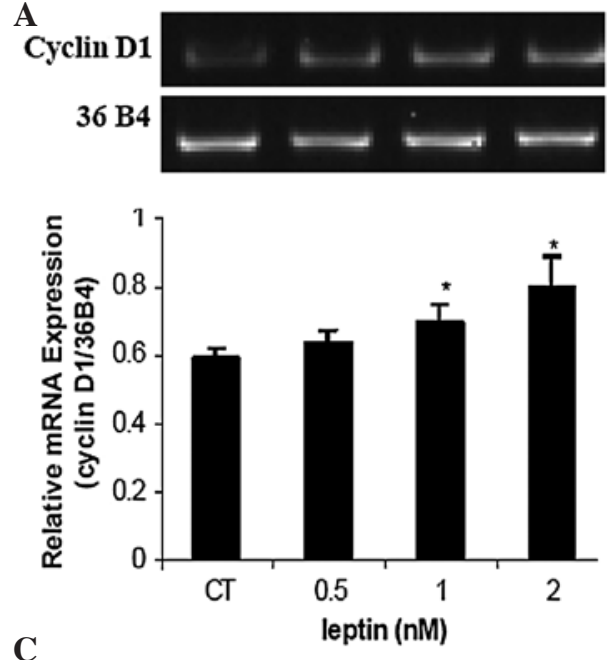

C
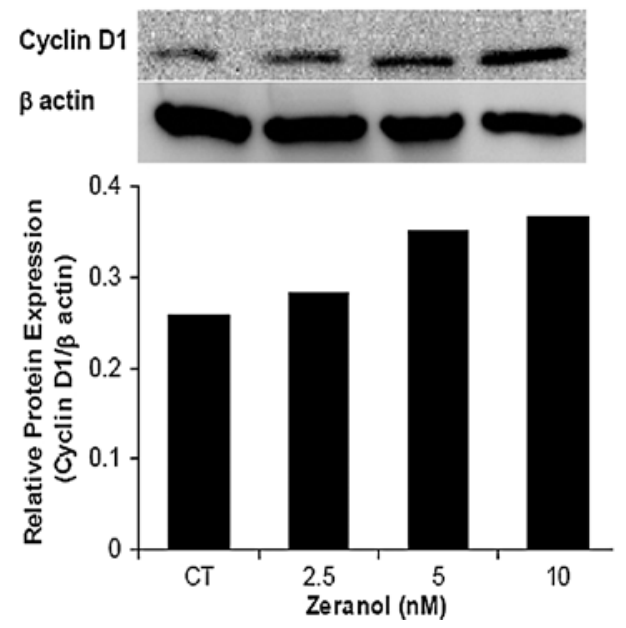

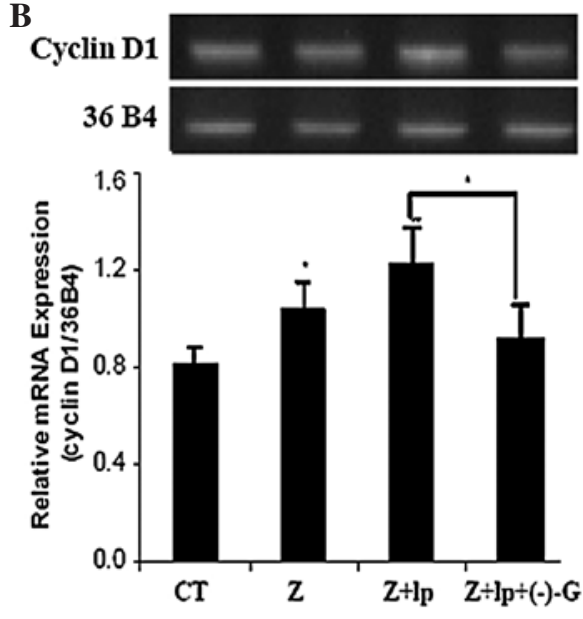

D
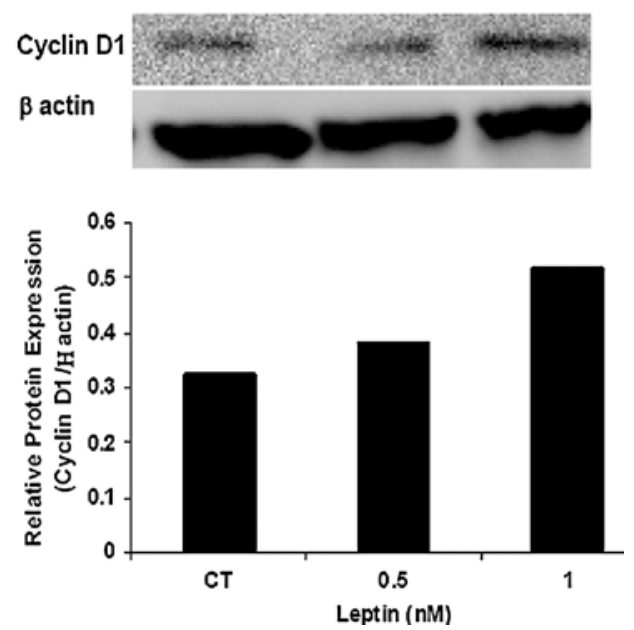

Figure 3. (A) Leptin increased cyclin D1 mRNA expression in HNBPADs. HNBPADs were treated with $0.5,1$ and 2 nM leptin for 24 h, then cyclin D1 mRNA expression was tested. A significant difference was found. Leptin at 1 and $2 \mathrm{nM}$ significantly increased cyclin D1 expression in the HNBPADs compared to the control group (p<0.05). (B) Cyclin D1 mRNA expression in HNBPADs. HNBPADs were treated with $1.5 \mathrm{nM}$ leptin, $3 \mathrm{nM} Z$ and $3 \mu \mathrm{M}(-)$-gossypol for $24 \mathrm{~h}$, and then mRNA was extracted. Cyclin D1 was amplified. Compared to the control group, $3 \mathrm{nM} \mathrm{Z}$ and the combination of $3 \mathrm{nM} Z$ with $1.5 \mathrm{nM}$ leptin significantly increased cyclin D1 expression, while $3 \mu \mathrm{M}(-)$-gossypol counteracted this effect. A significant difference was found between the combination groups with and without (-)-gossypol (p<0.05). (C) Z up-regulated cyclin D1 expression in HNBPADs. Primary cultured HNBPADs were treated with $2.5,5$ and 10 nM Z for 24 h, or with $0.1 \%$ DMSO as a control. Protein was extracted and Western blotting was performed. (D) Leptin up-regulated cyclin D1 expression in HNBPADs. Primary cultured HNBPADs were treated with 0.5 and $1 \mathrm{nM}$ leptin for $24 \mathrm{~h}$, or with $0.1 \%$ DMSO as a control. Protein was extracted and Western blotting was performed.

is overexpressed in hyperplasia and intraductal carcinoma of the breast (25). Due to its established role as a major human oncogene, the therapeutic use of cyclin D1 warrants further investigation.

Cyclin D1 levels are modulated by changing growth factors in culture medium. Leptin stimulates breast cancer cell growth by up-regulating cyclin D1 expression (10). Moreover, Garofalo et al found that leptin modulates both estrogen synthesis and ER $\alpha$ activity $(11,12)$. Besides controlling the cell cycle, cyclin D1 was found to be associated with ER (24). Cyclin D1 binds to the ER and stimulates its transcriptional activities. The cyclin D1 and ER complex may play a role in stimulating tumor cell proliferation. Since leptin stimulates estrogen biosynthesis through the induction of aromatase activity and the modulation of ER $\alpha$ activity, it has been characterized as a growth factor for breast cancer (11). High levels of leptin in obese breast cancer patients may play a crucial role in breast cancer cell proliferation, invasion and metastasis $(11,27)$. Leptin stimulates breast cancer cell growth by up-

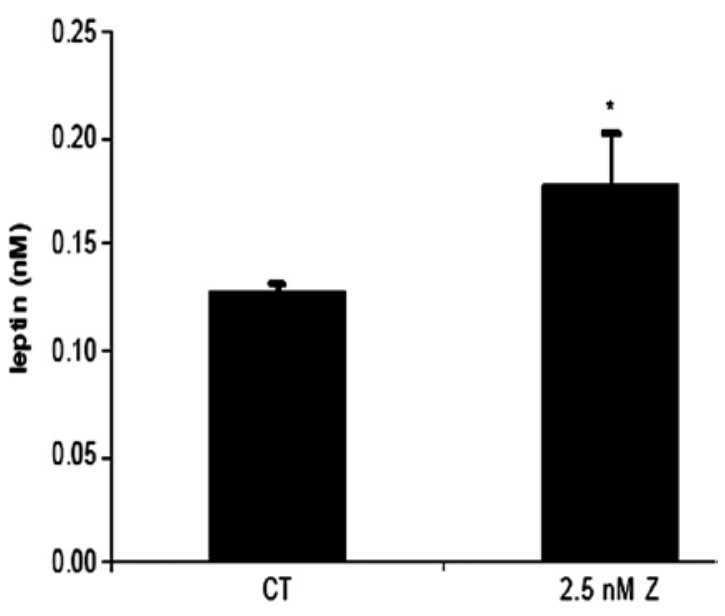

Figure 4. Z stimulates leptin secretion of primary cultured HNBPADs. Primary cultured HNBPADs (1x10 /well) were treated with $2.5 \mathrm{nM} \mathrm{Z}$ for $24 \mathrm{~h}$, and then the culture medium was collected. A human leptin immunoassay was conducted. $\mathrm{Z}$ at $2.5 \mathrm{nM}$ significantly increased leptin secretion of the HNBECs compared to the control group $(* \mathrm{p}<0.05)$. 
regulating cyclin D1 expression. It was also reported that leptin directly inhibits the maturation of 3T3-L1 pre-adipocytes, but cannot directly induce adipocyte apoptosis (18).

In our cell proliferation assay, leptin increased HNBPAD growth in a dose-dependent manner (Fig. 1A), and HNBPADs were more sensitive to leptin than HNBECs (Fig. 1B). This is to be expected, as leptin is mainly secreted by adipocytes, which are differentiated from pre-adipocytes. According to Fig. 2A, pre-exposure to $6 \mathrm{nM}$ of leptin resulted in a HNBPAD reaction to a lower dose of $\mathrm{Z}$, while $1.25 \mathrm{nM} \mathrm{Z}$ significantly increased the proliferation of HNBPAD exposed to $6 \mathrm{nM}$ leptin, and $2.5 \mathrm{nM} \mathrm{Z}$ began to significantly increase the proliferation of HNBPADs isolated from non-leptin cultured tissues. As shown in Fig. 2B and C, ZS also increased the proliferation of HNBPADs isolated from non-leptin and 6-nM leptin cultured tissue. Comparing Fig. $2 \mathrm{~B}$ and $\mathrm{C}$, it is clear that the preadipocytes isolated from 6-nM leptin cultured tissue were more sensitive to ZS-D30 than to ZS-D0. A significant difference between ZS-D0 and ZS-D30 was found in the proliferation of HNBPADs isolated from 6-nM leptin cultured tissue. This result implies that leptin increased HNBPAD sensitivity to ZS-D30, since HNBPADs isolated from leptin cultured tissue grew faster than those isolated from non-leptin cultured tissue. It is suggested that leptin stimulates primary cultured HNPAD growth, while $\mathrm{Z}$ and ZS improve leptin-induced growth.

Based on the results shown in Fig. 2A, we hypothesized that cells isolated from 6-nM leptin cultured tissue had increased sensitivity to $\mathrm{Z}$ compared to those isolated from non-leptin cultured tissue. This can be partly explained by the fact that leptin up-regulated cyclin D1 expression (Fig. 3A). It is possible that obese women may be more sensitive to $\mathrm{Z}$ and $\mathrm{ZS}$ than average-weight women, due to the increased leptin level in obese women. Moreover, we also found that primary cultured normal human breast epithelial cells and MCF-7Adr cells increased cell sensitivity to $Z$ (3); thus, the adverse effect of $\mathrm{Z}$ to human health would probably be strengthened. However, our data revealed that (-)-gossypol counteracted this effect by down-regulating cyclin D1 expression (Fig. 3B).

On the other hand, Z not only up-regulated cyclin D1 expression, but also stimulated HNBPADs to secrete leptin and strengthened the action of leptin. This result indicates that $\mathrm{Z}$ may be more harmful to obese individuals than to individuals of average weight as it increases the risk of breast cancer (28). However, since (-)-gossypol reverses the effect of the combination of leptin with $\mathrm{Z}$ in HNBPADs, it may aid in the treatment of breast cancer, particularly in obese patients.

In summary, both leptin and $\mathrm{Z}$ appeared to increase HNBPAD growth by increasing cyclin D1 expression. Leptin improved HNBPAD sensitivity to $\mathrm{Z}$, and $\mathrm{Z}$ strengthened the effect of leptin by inducing HNBPADs to secrete leptin. (-)-gossypol counteracted the growth of primary cultured HNBPADs by down-regulating cyclin D1 mRNA expression. The mechanisms of this process will be further studied in future. Our report is the first to reveal that (-)-gossypol, a food component derived from cottonseed products, may serve as a potential chemopreventive agent to suppress the stimulatory effect of $\mathrm{Z}$ and leptin on normal human breast pre-adipocytes. Further investigation of the interactions between leptin and $\mathrm{Z}$ in normal human breast pre-adipocytes is currently in progress.

\section{Acknowledgements}

This study was supported by NIH grant R01 ES 015212.

\section{References}

1. Jemal A, Siegel R, Ward E, Hao Y, Xu J and Thun MJ: Cancer statistics, 2009. CA Cancer J Clin 59: 225-249, 2009.

2. Thorn SR, Meyer MJ, van Amburgh ME and Boisclair YR: Effect of estrogen on leptin and expression of leptin receptor transcripts in prepubertal dairy heifers. J Dairy Sci 90: 3742-3750, 2007.

3. Xu P, Ye W, Jen R, Lin SH, Kuo CT and Lin YC: Mitogenic activity of zeranol in human breast cancer cells is enhanced by leptin and suppressed by gossypol. Anticancer Res 29: 4621-4628, 2009.

4. Lorincz AM and Sukumar S: Molecular links between obesity and breast cancer. Endocr Relat Cancer 13: 279-292, 2006.

5. De Waard F, Baanders-Vanhalewijn EA and Huizinga J: The bimodal age distribution of patients with mammary carcinoma; evidence for the existence of 2 types of human breast cancer. Cancer 17: 141-151, 1964.

6. Kiess W, Petzold S, Topfer M, et al: Adipocytes and adipose tissue. Best Pract Res Clin Endocrinol Metab 22: 135-153, 2008.

7. Gullicksen PS, Della-Fera MA and Baile CA: Leptin-induced adipose apoptosis: implications for body weight regulation. Apoptosis 8: 327-335, 2003.

8. Calle EE and Thun MJ: Obesity and cancer. Oncogene 23: 6365-6378, 2004.

9. Cirillo D, Rachiglio AM, la Montagna R, Giordano A and Normanno N: Leptin signaling in breast cancer: an overview. J Cell Biochem 105: 956-964, 2008.

10. Chen C, Chang YC, Liu CL, Chang KJ and Guo IC: Leptininduced growth of human ZR-75-1 breast cancer cells is associated with up-regulation of cyclin D1 and c-Myc and downregulation of tumor suppressor p53 and p21WAF1/CIP1. Breast Cancer Res Treat 98: 121-132, 2006.

11. Garofalo C, Koda M, Cascio S, et al: Increased expression of leptin and the leptin receptor as a marker of breast cancer progression: possible role of obesity-related stimuli. Clin Cancer Res 12: 1447-1453, 2006.

12. Garofalo C and Surmacz E: Leptin and cancer. J Cell Physiol 207: 12-22, 2006.

13. Rose DP, Komninou D and Stephenson GD: Obesity, adipocytokines, and insulin resistance in breast cancer. Obes Rev 5: 153-165, 2004.

14. Ishikawa $\mathrm{M}$, Kitayama $\mathrm{J}$ and Nagawa $\mathrm{H}$ : Enhanced expression of leptin and leptin receptor (OB-R) in human breast cancer. Clin Cancer Res 10: 4325-4331, 2004.

15. Laud K, Gourdou I, Pessemesse L, Peyrat JP and Djiane J: Identification of leptin receptors in human breast cancer: functional activity in the T47-D breast cancer cell line. Mol Cell Endocrinol 188: 219-226, 2002.

16. Goodwin PJ, Ennis M, Fantus IG, Pritchard KI, Trudeau ME, Koo $\mathrm{J}$ and Hood N: Is leptin a mediator of adverse prognostic effects of obesity in breast cancer? J Clin Oncol 23: 6037-6042, 2005.

17. Garofalo C, Sisci D and Surmacz E: Leptin interferes with the effects of the antiestrogen ICI 182,780 in MCF-7 breast cancer cells. Clin Cancer Res 10: 6466-6475, 2004.

18. Ambati S, Kim HK, Yang JY, Lin J, Della-Fera MA and Baile CA: Effects of leptin on apoptosis and adipogenesis in 3T3-L1 adipocytes. Biochem Pharmacol 73: 378-384, 2007.

19. Zhang M, Liu H, Guo R, et al: Molecular mechanism of gossypol-induced cell growth inhibition and cell death of HT-29 human colon carcinoma cells. Biochem Pharmacol 66: 93-103, 2003.

20. Shidaifat F, Canatan H, Kulp SK, et al: Inhibition of human prostate cancer cells growth by gossypol is associated with stimulation of transforming growth factor-beta. Cancer Lett 107: 37-44, 1996.

21. Gilbert NE, O'Reilly JE, Chang CJ, Lin YC and Brueggemeier RW: Antiproliferative activity of gossypol and gossypolone on human breast cancer cells. Life Sci 57: 61-67, 1995.

22. Ye W, Chang HL, Wang LS, et al: Modulation of multidrug resistance gene expression in human breast cancer cells by (-)-gossypol-enriched cottonseed oil. Anticancer Res 27: 107-116, 2007. 
23. Ye W, Xu P, Threlfall WR, et al: Zeranol enhances the proliferation of pre-adipocytes in beef heifers. Anticancer Res 29: 5045-5052, 2009.

24. Roy PG and Thompson AM: Cyclin D1 and breast cancer. Breast 15: 718-727, 2006.

25. Alle KM, Henshall SM, Field AS and Sutherland RL: Cyclin D1 protein is overexpressed in hyperplasia and intraductal carcinoma of the breast. Clin Cancer Res 4: 847-854, 1998

26. Sutherland RL, Prall OW, Watts CK and Musgrove EA: Estrogen and progestin regulation of cell cycle progression. J Mammary Gland Biol Neoplasia 3: 63-72, 1998.
27. Hu X, Juneja SC, Maihle NJ and Cleary MP: Leptin - a growth factor in normal and malignant breast cells and for normal mammary gland development. J Natl Cancer Inst 94: 1704-1711, 2002.

28. Yuri T, Tsukamoto R, Miki K, Uehara N, Matsuoka Y and Tsubura A: Biphasic effects of zeranol on the growth of estrogen receptor-positive human breast carcinoma cells. Oncol Rep 16: 1307-1312, 2006. 